\title{
Intestinal synthesis of vitamins of the B complex in chicks
}

\author{
By MARIE E. COATES, J. E. FORD AND G. F. HARRISON \\ National Institute for Research in Dairying, Shinfield, Reading
}

(Received 18 December 1967-Accepted 6 March 1968)

\begin{abstract}
I. Chicks were reared in germ-free and conventional environments on diets devoid of one of each of the following vitamins : riboflavine, pantothenic acid, vitamin $B_{6}$, vitamin $B_{12}$, folic acid, nicotinic acid, thiamine or biotin. When marked signs of deficiency began to appear the birds were killed. The livers and caecal contents were removed and assayed microbiologically for the vitamin omitted from the diet.

2. Negligible quantities of the omitted vitamin were detected in the caecal contents of the germ-free birds, but considerable amounts were found in corresponding samples from conventional birds. There was little evidence that signs of deficiency were less severe in the conventional birds.

3. It was concluded that all the vitamins tested were synthesized by microbial action in the gut of conventional birds but that the birds derived little benefit from the synthesized vitamins, with the possible exception of folic acid.

4. There were indications that the requirements for thiamine and pantothenic acid were higher in conventional than in germ-free chicks.
\end{abstract}

Experiments with conventional animals have provided many indications that some vitamins are produced in the alimentary tract as a result of microbial activity. For instance, in coprophagous animals such as the rat and the guinea-pig omission from the diet of vitamins of the B complex does not result in signs of deficiency unless coprophagy is prevented or antibacterial agents (e.g. sulphonamides) are given in the diet. The vitamin requirement of chickens reared in contact with their excreta is partly satisfied by ingestion of their own droppings. Inclusion of low levels of antibiotics in the diet of chicks or rats 'spares' the need for certain vitamins, an effect probably mediated through the intestinal microflora.

The present investigation was undertaken to determine the extent of vitamin synthesis in the alimentary tract of the chick, and of the availability of the vitamins to the bird.

\section{MATERIALS AND METHODS}

Chicks

Chicks of the Rhode Island Red $\times$ Light Sussex cross were used. For the experiment on vitamin $B_{12}$ deficiency, eggs were taken from hens given a diet low in vitamin $B_{12}$ in order to reduce the amount carried over from the dam to the chick. For the other experiments eggs were taken from hens given a normal breeders' ration. Each experiment was done on comparable groups of germ-free and conventional chicks.

The eggs were incubated in a commercial incubator for 18 days, then candled and treated by the disinfection process described by Coates, Fuller, Harrison, Lev \& Suffolk ( 1963$)$. Half were immediately introduced into Gustafsson isolators and half were replaced in the conventional incubator to hatch. After hatching, the germ-free 
chicks were distributed, four to a cage, in stainless steel cages fitted with wire-screen floors inside the isolators. Corresponding conventional birds were allotted to similar cages in a room where the environmental conditions of temperature, humidity and lighting could be controlled to match those inside the isolators.

As far as possible males and females were distributed evenly throughout the experimental groups. A total of from twelve to thirty-two birds was used on each treatment.

\section{Diet}

The diet had the following percentage composition: vitamin-low casein (Fisons Pharmaceuticals Ltd, Loughborough) 18 , gelatin 10 , maize starch 60.25 , salt mixture 6, L-cystine 0.3 , choline chloride 0.15 , inositol $0 \cdot 1$, vitamin supplement 0.2 , maize oil 5 . In each $100 \mathrm{~g}$ diet the salt mixture provided $\mathrm{CaCO}_{3} \mathrm{I} \cdot 5 \mathrm{~g}, \mathrm{~K}_{2} \mathrm{HPO}_{4} \mathrm{I} \cdot 6 \mathrm{I} \mathrm{g}, \mathrm{CaHPO}_{4}$. ${ }_{2} \mathrm{H}_{2} \mathrm{O}_{1} \cdot 37 \mathrm{~g}, \mathrm{NaCl} 0.837 \mathrm{~g}, \mathrm{MnSO}_{4} .4 \mathrm{H}_{2} \mathrm{O}_{25} \mathrm{mg}, \mathrm{KI} 4 \mathrm{mg}, \mathrm{CuSO}_{4} \cdot{ }_{5} \mathrm{H}_{2} \mathrm{O}_{\mathrm{I}} \cdot 5 \mathrm{mg}$, $\mathrm{ZnCl}_{2} \times 25 \mathrm{mg}$; the fat-soluble vitamins were dissolved in the maize oil to give retinol (vitamin A) 6800 i.u., cholecalciferol (vitamin $\mathrm{D}_{3}$ ) $\mathrm{r} 60 \mathrm{i} . \mathrm{u}$, menaphthone $500 \mu \mathrm{g}$, $\alpha$-tocopheryl acetate I $\mathrm{mg}$ per $100 \mathrm{~g}$ diet; the vitamin supplement supplied thiamine hydrochloride $\mathrm{I} \cdot 2 \mathrm{mg}$, riboflavine $2.4 \mathrm{mg}$, calcium pantothenate $6 \mathrm{mg}$, pyridoxol hydrochloride $\mathrm{I} \cdot 6 \mathrm{mg}$, biotin $80 \mathrm{mg}$, nicotinic acid $16 \mathrm{mg}$, pteroylmonoglutamic acid $300 \mu \mathrm{g}$, cyanocobalamin $8 \mu \mathrm{g}$ in each $100 \mathrm{~g}$ diet.

When a diet deficient in any one vitamin was required, that vitamin was omitted from the supplement. It is likely, however, that the casein contributed minute traces of some of the vitamins that could not be completely removed in the course of its preparation. After the diets had been mixed they were made into granules by moistening with water, pressing through a no. 4 sieve, and drying in a current of air below $45^{\circ}$. They were packed into plastic bags and sterilized by $\gamma$-irradiation at 5 Mrad.

\section{Experimental procedure}

Experiments were done with diets devoid of riboflavine, vitamin $B_{6}$, pantothenic acid, vitamin $B_{12}$, folic acid, nicotinic acid, thiamine or biotin. The birds were given the experimental diets from I day of age. They were weighed on the Ist day, then at weekly intervals. The experiments were terminated as soon as there was evidence of severe deficiency. In most instances this usually occurred about the 2 nd week when, although no specific signs were observed, the birds were in very poor condition and a few had already died. Deficiencies of vitamin $\mathrm{B}_{12}$ and of biotin were not clearly shown until the $4^{\text {th }}$ week. The surviving birds were weighed and killed, and the livers and caecal contents of the birds in each cage were combined for microbiological assay. Thus when no birds had died the assays were done on the combined samples from four birds, but in experiments where there was a high mortality a smaller number was represented in the combined samples. In the folic acid study, haemoglobin was determined by the oxyhaemoglobin method on individual samples taken from the wing vein of all survivors.

After the main comparative experiments had been completed, information was required about the reserves of riboflavine and folic acid carried over from the eggs to 
the newly hatched chicks, and their possible influence on the liver levels at the end of the experimental period. Yolk sacs and livers were removed from twenty freshly killed I-day-old chicks and four pooled samples, each from five birds, were assayed for riboflavine and folic acid. Groups of twenty chicks from the same hatch were reared in a conventional environment on diets devoid of either riboflavine or folic acid for the same length of time as in the main experiments ( 19 and 12 days, respectively). The birds were then killed and the amount of the omitted vitamin was determined in four combined samples of five livers.

\section{Microbiological assays}

Riboflavine was assayed with Lactobacillus casei ATCC 7469 by the method of Roberts \& Snell (1946). Pantothenic acid was released from the test samples by the enzymic procedure of Novelli \& Schmetz (I95I) and assayed with $L b$. plantarum ATCC 8014 by the method described in US Pharmacopeia XVI ( 17 th revise), I960, p. 87 I. Vitamin $\mathrm{B}_{6}$ was assayed with Kloeckera brevis $\mathrm{B} 768$ as described by Barton-

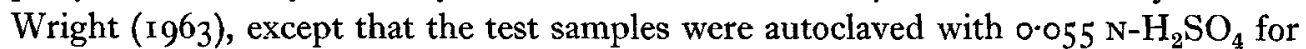
$5 \mathrm{~h}$ at $126^{\circ}$ as recommended by Rabinowitz \& Snell (1947), and were not predigested with takadiastase. Vitamin $\mathrm{B}_{12}$ was assayed with Ochromonas malhamensis by the method of Ford (1953). Folic acid activity was measured with $L$ b. case $i$ by an adaptation of the procedure recommended by Herbert (I96I) for the assay of folic acid in blood serum. Thiamine was assayed with Lactobacillus viridescens, as described by Deibel, Evans \& Niven (1957), and nicotinic acid and biotin with $\mathrm{Lb}$. plantarum as described by Barton-Wright (1963).

\section{RESULTS}

The results of all experiments comparing germ-free and conventional chicks are summarized in Table $I$. The assay procedures were not sufficiently sensitive to establish the presence of riboflavine, vitamin $B_{6}$ or pantothenic acid in the caecal contents of the germ-free animals. The values given for these three vitamins represent the largest amounts that might have been present. For the remainder of the vitamins the values given are more exact and are based on apparently valid assays. The significance of the difference between germ-free and conventional birds in caecal and liver contents was calculated by Student's $t$ test.

In most experiments the deficiency developed so rapidly that the birds became moribund before any signs typical of the particular deficiency (cf. Coates, Kon \& Shepheard, 1950) were observed. On the diet devoid of biotin, however, two of the germ-free birds developed scaly feet and two had perosis; one of the corresponding conventional birds had perosis and none had scaly feet. In the experiment without folic acid, all birds had a lowered haemoglobin value. The mean blood levels, in $\mathrm{mg} / \mathrm{I} 00 \mathrm{ml}$, with standard errors in parentheses, were: germ-free $6.56(0.264)$, conventional $7.23(0 \cdot 146)$. The difference, calculated on individual values by Student's $t$ test, was significant $(0.05>P>0.02$, with 14 degrees of freedom). 


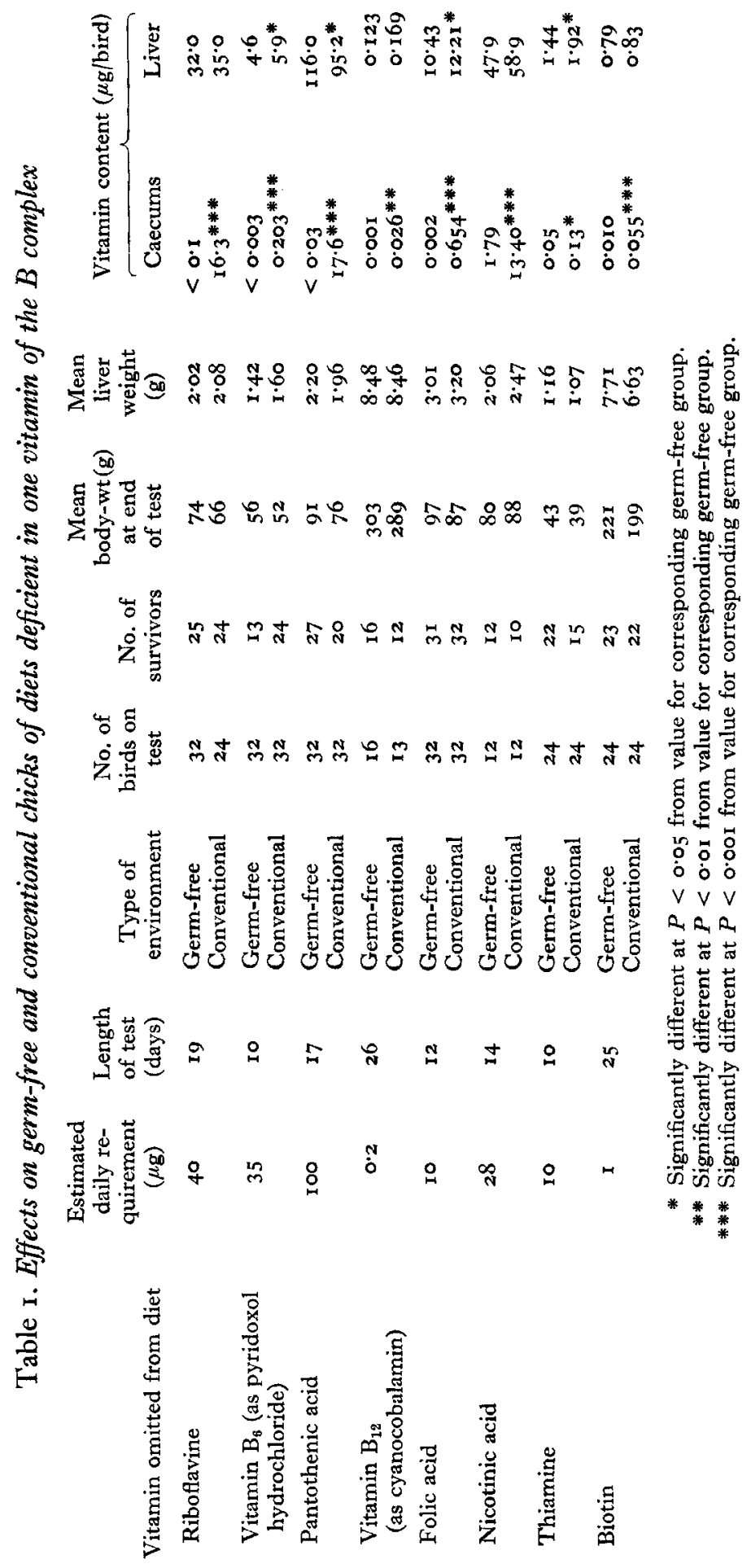


In the experiments with conventional chicks to investigate the reserves carried over from the egg, the amounts of riboflavine and folic acid, calculated in $\mu \mathrm{g} / \mathrm{bird}$, were:

$\begin{array}{lccc}\text { Yolk sacs } & \begin{array}{c}\text { Livers of } \\ \text { day-old birds }\end{array} & \begin{array}{c}\text { Livers at end } \\ \text { of experiment }\end{array} \\ \text { Riboflavine } & 80 & 25 & 34 \\ \text { Folic acid } & 1 \cdot 5 & 5 \cdot 1 & 7 \cdot 5\end{array}$

\section{DISCUSSION}

In all experiments the content of the vitamin omitted from the test diet was considerably greater in the caecums of the conventional birds. Except for nicotinic acid, the vitamin levels in the caecums of the germ-free birds were near or below the lower limit of sensitivity of the microbiological assays. The small amounts that were present may have been contributed by traces in the diet or in digestive secretions or desquamated epithelial cells; the comparatively higher content of nicotinic acid was probably the result of its endogenous synthesis from dietary tryptophan. In every instance the caecums of corresponding conventional birds contained relatively large quantities of the omitted vitamin, which must have been produced by the action of microorganisms in the alimentary tract. The pattern of vitamin synthesis was very similar to that observed by Kon \& Porter (1953) in the rumen contents of steers given a lowvitamin diet, in that the concentrations of riboflavine, pantothenic acid and nicotinic acid were much higher than that of thiamine, vitamin $B_{6}$, biotin or folic acid.

Since the birds were housed on wire screen floors they did not have access to their own droppings, and the microbially synthesized vitamins could only have been available to them through direct absorption from the digestive tract. Estimated daily requirements of the chick for vitamins of the $B$ complex, based on the National Research Council (I960) and Agricultural Research Council (I963) recommendations, are given in Table 1 . Comparison with these values shows that the amounts of riboflavine, nicotinic acid, pantothenic acid and, possibly, vitamin $B_{12}$ present in the caecums could, if absorbed, have made a significant contribution to the bird's requirement. The relatively smaller amounts of the other vitamins might indicate a lower rate of synthesis or a more rapid absorption from the caecums.

Absorption of significant amounts of the synthesized vitamin would be reflected in alleviation of specific signs of deficiency, increased growth, lower mortality and, possibly, higher stores in the liver, but attempts to assess the uptake of the vitamins in these terms were inconclusive. In only two of the experiments was it possible to detect signs characteristic of deficiency of a particular vitamin, and in both instances the conventional birds were less severely affected. On the diet without folic acid the haemoglobin level was significantly $(P=0.02)$ lower in the blood of germ-free birds; on the diet without biotin two germ-free birds developed the scaly feet typical of biotin deficiency but none was afflicted in the conventional group. With the exception of the birds deprived of nicotinic acid, growth rate was not apparently improved as a result of vitamin synthesis in the gut. On the contrary, the body-weights of germ-free birds were consistently higher than those of their conventional counterparts. This finding is in agreement with the results of experiments with chicks given adequate 
diets, where growth was invariably better in a germ-free environment (Forbes $\&$ Park

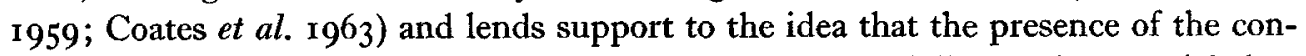
ventional microflora prevents the bird from developing its full growth potential. Any uptake of the microbially synthesized vitamins that may have occurred in the conventional birds was apparently not enough to overcome the adverse effect of the flora on growth. Mortality on the diets deficient in riboflavine or vitamin $\mathrm{B}_{6}$ was considerably higher in the germ-free groups. This may indicate some protective effect of the vitamins synthesized in the gut of conventional chicks, but could also be the result of a higher demand for the vitamins by the more rapidly growing germ-free birds. In contrast, mortality was much higher in the conventional groups on diets deficient in thiamine or pantothenic acid.

Measurement of liver reserves again failed to provide any very conclusive evidence for absorption. There were only small differences between the vitamin contents of the germ-free and conventional livers. In almost every instance the conventional livers contained higher amounts of the omitted vitamin, although the difference was significant only in the experiments with vitamin $B_{6}$, folic acid and thiamine deficiency. The exception was pantothenic acid, which was present in significantly lower quantity in the conventional livers. Gordon (1959) has reported that germ-free chicks have smaller livers than conventional birds. In our experiments little difference was observed between the liver weights, but when calculated as a percentage of body-weight, the livers of the germ-free birds were, in general, smaller.

These results provide direct evidence for the synthesis of riboflavine, vitamin $B_{6}$, pantothenic acid, vitamin $B_{12}$, folic acid, nicotinic acid, thiamine and biotin by microbial action in the gut of the chick. They also indicate that some of the effects of deficiency of riboflavine, vitamin $\mathrm{B}_{6}$, folic acid and nicotinic acid might have been very slightly alleviated by the microbially synthesized vitamins, although for all practical purposes the contribution to the bird's requirement was negligible. The experiments were done under laboratory conditions and may not be directly applicable to more practical forms of management. It is well-known, for instance, that chicks kept on deep litter can derive some benefit from the products of microbial synthesis through the intake of their own droppings. Our results are in accord with those of Miller \& Luckey (1963), who reported that chicks reared on a diet low in folic acid and mono-associated with a strain of Escherichia coli had higher haemoglobin values and tissue levels of folic acid than their germ-free counterparts, even though coprophagy was prevented. Similarly, Daft, McDaniel, Harman, Romine \& Hegner (1963) demonstrated that rats prevented from coprophagy were able to utilize folic acid, but not pantothenic acid, synthesized by microbial action in the alimentary tract.

Some of the observations mentioned above need further comment. The higher mortality among the conventional birds on the diets devoid of thiamine or pantothenic acid suggests that they have a greater requirement for these two vitamins than their germ-free counterparts. In the birds deprived of thiamine, liver levels of the vitamin were higher $(P<0.05)$ in the conventional group. Such a result might be expected if thiamine had been absorbed by the conventional chicks or if the higher death rate had selectively removed birds with lower reserves. However, Wostmann, Knight, 
Keeley \& Kan (1963) reported consistently higher liver reserves of thiamine in conventional compared with germ-free rats; this difference could not be fully accounted for by differences in the absorption of microbially synthesized thiamine or in mortality rates. They suggested that liver thiamine levels might be dependent on metabolic activity; the lack of a microflora, and hence of the need to detoxify its products, might decrease the metabolic activity of the liver and consequently its energy requirement and thiamine content. A similar argument could explain the lower requirement for thiamine of the germ-free chick. Desplaces, Zagury \& Sacquet (1963) and Levenson, Kan, Lev \& Doft ( 1966 ) found that the basal metabolic rate was $15-20 \%$ lower in germ-free than in conventional rats. If the same is true of chicks, a smaller need for thiamine might be expected in the germ-free birds. A higher demand for pantothenic acid by conventional chicks is less readily accounted for, but could be the result of alterations in lipid metabolism, known to occur in the germ-free state. Another explanation might be found in the role of pantothenic acid in adrenal cortical functions (Ralli \& Dumm, I953), in view of the report of Miyakawa (I966) that the adrenals of germ-free rats are smaller than those of conventional rats. It seems possible that the microbial burden of the conventional animal could lead to increased demands for adrenal steroids, resulting in an increase in size of the glands and a greater requirement for pantothenic acid.

In all our experiments it was somewhat surprising to find that although the birds, whether germ-free or conventional, were showing marked signs of deficiency at the time they were killed, the livers nevertheless contained appreciable quantities of the vitamin omitted from the diet. The levels found were, in fact, very similar to published values for normal birds (Long, I96I). The possibility that they represented reserves carried over from the egg was investigated, with regard to riboflavine and folic acid, in experiments with conventional birds. The reserves of riboflavine in the yolk sacs and livers of newly hatched chicks could more than account for the quantity found at the end of the period of deprivation, but the evidence with folic acid was less clearcut. The problem needs further investigation in germ-free birds. Luckey, Pleasants, Wagner, Gordon \& Reyniers (1955) produced evidence for tissue synthesis of folic acid in germ-free rats. From our own findings presented here there is a strong indication that some synthesis of nicotinic acid occurs even in the absence of a microflora and the possibility of endogenous synthesis of other vitamins cannot be entirely dismissed. The liver content of the omitted vitamin was measured in the expectation that it would provide an index of the state of deficiency of the chicks, and no account was taken of the amounts of vitamin in the rest of the carcass. It is clear from the results that the question of endogenous synthesis needs further investigation by means of precise balance studies, in which the reserves of each vitamin carried over from the egg, together with traces in the diet, can be related to the amounts found in germ-free birds after a period of deprivation. Whatever the source of the vitamins, in an extreme state of deficiency their relatively high concentration in the liver seems to be related to the physiological requirement for metabolic function rather than to the use of the liver as a storage organ. 
We are grateful to Dr R. Fuller for sterility checks on the germ-free birds, to Mr J. P. Fordham and Mr D. A. F. Miles for skilled management of the isolators and care of the chicks, and to Mr K. J. Scott and Mrs E. Rivers for technical assistance with the microbiological assays.

\section{REFERENCES}

Agricultural Research Council (1963). The Nutrient Requirements of Farm Livestock. No. 1. Poultry, p. 26. London: Agricultural Research Council.

Barton-Wright, E. C. ( 1963$)$. Practical Methods for the Microbiological Assay of the Vitamin B Complex and Amino Acids. London: United Trade Press Ltd.

Coates, M. E., Fuller, R., Harrison, G. F., Lev, M. \& Suffolk, S. F. (rg63). Br. F. Nutr. 17, I4I.

Coates, M. E., Kon, S. K. \& Shepheard, E. E. (1950). Br. F. Nutr. 4, 203.

Daft, F. S., McDaniel, E. G., Harman, L. G., Romine, M. K. \& Hegner, J. R. (1963). Fedn Proc. Fedn Am. Socs exp. Biol, 22, 129.

Deibel, R. H., Evans, J. B. \& Niven, C. F. (1957). F. Bact. 74, 818.

Desplaces, A., Zagury, D. \& Sacquet, E. (1963). C. r. hebd. Séanc. Acad. Sci., Paris 257, 756.

Forbes, M. \& Park, J. T. (1959). \%. Nutr. 67, 69.

Ford, J. E. (1953). Br. Y. Nutr. 7, 299.

Gordon, H. A. (1959). Ann. N.Y. Acad. Sci. 78, 208.

Herbert, V. (196r). F. clin. Invest. 40, 81.

Kon, S. K. \& Porter, J. W. G. (1953). Proc. Nutr. Soc 12, xiI.

Levenson, S. M., Kan, D., Lev, M. \& Doft, F. S. (r 966). Fedn Proc. Fedn Am. Socs exp. Biol. $25,482$.

Long, C. (editor). (196I). In Biochemists' Handbook, p. 683. London: E. and F. N. Spon.

Luckey, T. D., Pleasants, J. R., Wagner, M., Gordon, H. A. \& Reyniers, J. A. (1955). F. Nutr. 57, 169.

Miller, H. T. \& Luckey, T. D. (1963). F. Nutr. 80, 236.

Miyakawa, M. (ı 966). Int. Congr. Microbiol. Ix. Moscow. Symposia, p. 287.

National Research Council (I 960). Publs natn. Res. Coun., Wash. no. 827.

Novelli, G. D. \& Schmetz, F. J. Jr. (195I). F. biol. Chem. 192, r8r.

Rabinowitz, J. C. \& Snell, E. E. (1947). Ind. Engng Chem. analyt. Edn I9, 277.

Ralli, E. P. \& Dumm, M. E. (1953). Vitams Horm. I1, I33.

Roberts, E. C. \& Snell, E. E. (r946). F. biol. Chem. 163, 499.

Wostmann, B. S., Knight, P. L., Keeley, L. L. \& Kan, D. F. (1963). Fedn Proc. Fedn Am. Socs exp. Biol. 22, 120 . 